\title{
ПЕРЕВОДЧЕСКИЕ ТРАНСФОРМАЦИИ В ТЕКСТАХ ПЕРЕВОДА ОФИЦИАЛЬНОГО САЙТА ПАО «АЛРОСА»
}

\section{TRANSFORMATIONS IN TRANSLATION OF TEXTS IN THE OFFICIAL SITE OF ALROSA PJSC}

\section{R. Ivanova}

A. Salgynova

Summary: The article is devoted to the study of translation transformations in the texts of the official website of Alrosa PJSC. The authors investigate the influence of transformations on the adequacy of the translation, and also consider the frequency of the translator's use of various types of transformations in order to identify the most successful techniques. The percentage of applied transformations is displayed and analyzed.

Keywords: translation transformations, translation adequacy, English, text.

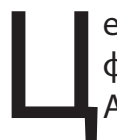

лью статьи является анализ переводческих трансформаций в текстах перевода официального сайта АК «Алроса» ПАО.

Актуальность работы обусловлена интересом к адекватному переводу официальной информации предприятий в сетевом пространстве в свете глобализации и информатизации мирового сообщества.

Понятие «переводческая трансформация» имеет несколько определений. Так, В.Н. Комиссаров в своей работе называет переводческую трансформацию «преобразованием, с помощью которого можно осуществить переход от единиц оригинала к единицам перевода в указанном смысле» [Комиссаров, 1990].

Л.С. Бархударов под трансформацией понимает «преобразование, которое может употребляться только тогда, когда преобразование используется в общем описании языка, например, если речь идет между языковыми и речевыми единицами, где одна является исходной, а другая основывается на первой» [Бархударов, 1975].

Понятие переводческой трансформации А.Д. Швейцера имеет схожесть с трактовкой Бархударова. В своей работе он писал, что «переводческая трансформация это отношение между исходным и переводимым языками, в процессе которого меняется форма выражения с одной в другую» [Швейцер, 1973].
Иванова Раиса Петровна

К.филол.н., Политехнический институт (филиал) ФГАОУ ВО «Северо-Восточный федеральный университет им. М.К. Аммосова» в г. Мирном Raissa1@yandex.ru

Салгынова Александра Александровна Политехнический институт (филиал) ФГАОУ ВО «СевероВосточный фредеральный университет им. М.К. Аммосова» в г. Мирном salgynova18@gmail.com

Аннотация: Статья посвящена изучению переводческих трансформаций в текстах перевода официального сайта АК «Алроса» ПАО. Авторы исследуют влияние трансформаций на адекватность перевода, а также рассматривают частотность употребления переводчиком различных типов трансформаций с целью выявления наиболее успешных приемов. Выводится процентное соотношение применяемых трансформаций и приводится его анализ.

Ключевые слова: переводческие трансформации, адекватность перевода, английский язык, текст.

На основании трудов Л.С. Бархударова и А.Д. Швейцера, Г.К. Гарбовский определяет переводческую трансформацию как «процесс перевода, где переводчик воспринимает и понимает смысл исходного текста, затем трансформирует речевую форму естественным путем, с помощью межъязыковой асимметрии, и в итоге получает аналогичную по смыслу текст» [Гарбовский, 2004].

В своей работе мы рассматриваем переводческие трансформации на материале официального сайта АК «Алроса» ПАО.

Обратим внимание на репрезентативные примеры, в которых информация коррелирует в обоих вариантах и является равноценной.

1. Основные объекты АЛРОСА по добыче и обработке алмазного сырья располагаются в двух российских регионах: в Республике Саха (Якутия), где Групnа ведет добычу в карьерах, рудниках и на россыпях, а также в Архангельской области на северо-западе страны, где добыча ведется карьерным способом.

ALROSA's main mining and processing operations are located in two Russian regions: the Republic of Sakha (Yakutia) and the Arkhangelsk region in the northwest of the Russian Federation. The company has open-pit and underground mining as well as alluvial operations in Yakutia, and there are only open-pit mines in the Arkhangelsk region. 
При анализе данного абзаца были выявлены следующие переводческие трансформации: членение предложения, конкретизация, генерализация, замена типа предложения, транслитерация, транскрипционный способ.

Особенностью английского языка является фиксированный порядок слов, поэтому переводчик разделил предложение на две части, чтобы не нарушать его. Также при членении предложения произошла замена типа предложения, в русской версии предложение было сложноподчиненным. Конкретизация была применена, чтобы не было путаницы, так как английское слово «country» имеет 2 определения по кембриджскому словарю: страна и деревня (сельская местность) [15]. Генерализация слова «группа» на «сотраnу» связана с тем, что в английском языке слово «group», при обозначении группы компаний, требует дополнительного слова, поэтому переводчик применил слово «сотраnу», которое имеет более общее значение. Также наблюдаем транслитерацию слова «АЛРОСА», транскрипционный перевод названий регионов Российской Федерации «Саха (Якутия)» и «Архангельский», что является характерным приемом при переводе имен собственных.

Данный перевод немного искажает информацию, так как в переводе не указан вид сырья, которую компания добывает и перерабатывает. Поэтому в начале предложения после слова main следует добавить определение diamond, чтобы не было информационной потери.

Рассмотрим следующий пример:

\section{2. МИРНИНСКИЙ ГОК}

Является старейшим горно-обогатительным комбинатом АЛРОСА и осуществляет добычу алмазов на следующих объектах:

- Рудник «Интернациональный». Введен в эксплуатацию с 1999 года. Характеризуется очень высоким содержанием алмазов в руде (8,09 карата на тонну).

— Рудник «Мир». Введен в эксплуатачию в 2009 году.

\section{MIRNYMPD}

The oldest mining and processing division of ALROSA, conducts diamond mining at the following deposits:

- Internatsionalny underground mine (since 1999) at Internatsionalnoye deposit is characterized by very high diamond grade (8.09 carats per ton).

- Mir underground mine (since 2009) at Mir deposit.

В данном отрывке наблюдается использование таких переводческих трансформаций, как дословный перевод, объединение предложений, транслитерация и конкретизация.
Объединение трех предложений: третье предложение «Введен в эксплуатацию с 1999 года» перемещено в скобку, тем самым сократив объем предложения, но и сохранив информацию. Также применена конкретизация при переводе слова «объекты» на «deposits», что в переводе означает месторождения, так как в предложении перечислены месторождения. Дословный перевод был применен во второй части предложения: осуществляет добычу алмазов на следующих объектах - conducts diamond mining at the following deposits, так как данные отрывки идентичны по своей структуре.

Название компании АЛРОСА переведено с помощью транслитерации, также и наименование рудников «Internatsionalnoye» и «Mir». Применение трансформаций оправдано, потерь не наблюдается.

\section{3. НЮРБИНСКИЙГОК}

Один из самых молодых горно-обогатительных комбинатов Группы ведет работы на Накынском рудном поле. ГОК осуществляет разработку следующих объектов:

- Карьер «Нюрбинский» (с 2002 года).

- Трубка «Ботуобинская». Открыта в 1994 году, находится в 3,3 км кюго-западу от трубки «Нюрбинская». Добыча руды открытым способом началась в 2015 году.

Аллювиальные россыпи. Россыпное месторождение «Нюрбинское» располагается в околотрубочном пространстве коренного месторождения алмазов одноименной трубки; россыпь «Ботуобинская» пространственно и генетически связана с одноименной трубкой и прилегает к ней с юго-западного фланга.

\section{NYURBA MPD}

One of the youngest MPD's of ALROSA Group, conducts mining at the Nakyn kimberlite field. Conducts diamond mining at the following deposits:

- Nyurbinsky open-pit (since 2001).

- Botuobinskaya pipe. Was discovered in 1994; the pipe is located $3.3 \mathrm{~km}$ southwest from Nyurbinskaya pipe. Open-pit mining started here in 2015.

Alluvial deposits. Nyurbinskoye placer deposit is located in the immediate vicinity of the primary kimberlite deposit of the same name; Botuobinskaya placer deposit is closely associated with the kimberlite pipe, both spatially and in origin, and adjoins the Botuobinskaya pipe on the southwest flank.

Переводческие трансформации: транслитерация, генерализация, конкретизация.

Наблюдается приём генерализации словосочетания «околотрубочном пространстве» на «the immediate vicinity», так как в английском языке нет эквивалента к слову «околотрубочном», в связи с этим, перевод- 
чик заменил его на слово с более широким значением «immediate». Для перевода имен собственных «Нюрбинский, Ботуобинская» применена транслитерация «Nyurbinsky, Botuobinskaya». Конкретизация русского прилагательного «рудное» на английское «kimberlite», связана с тем, что помимо кимберлитовых, существуют и лампроитовые месторождения. Примененные трансформации удачны, переводческих потерь не наблюдается.

Таким образом, анализ переводческих трансформаций в текстах перевода официального сайта АК «АЛРОСА» ПАО позволил сделать следующие выводы:

Всего было проанализировано 42 предложения исходного текста: 1692 печатных знаков. Из выявленнных 42 переводческих трансформаций, 24 - лексические трансформации, 18 - грамматические. Все переводческие трансформации были разобраны на примере 39 предложений текста перевода, так как при работе с текстом оригинала переводчик подверг объединению несколько предложений. Чаще всего переводчик использовал лексические трансформации (57\% от 100\%). Употребление данной трансформации связано с тем, что эквивалентных значений в языке перевода отсутствуют.

Из грамматических трансформаций больше всего была применена замена, что составляет $50 \%$ от общей суммы, что обусловлено тем, что в английском языке фиксированный порядок слов, и, чтобы придерживаться его, переводчик использовал замены типов предложения при переводе.

Объединение предложений занимает $22 \%$ от общей суммы, как и дословный перевод, в русском тексте присутствуют короткие предложения, которые переводчик объединил при переводе, при этом сохранил структуру английского языка.

В тексте присутствует всего одно членение предложения, так как в исходном языке одно предложение было очень сложным для перевода, из-за чего переводчик разделил его на 2 части, для упрощения восприятия информации.

Из лексических трансформаций большую часть занимает транслитерация (39\%). Такое большое использование транслитерации обусловлено тем, что в тексте было много имен собственных. Например, название компании, рудников и т.д.

При переводе с русского на английский чаще всего используется генерализация (26\%), нежели чем конкретизация, так как лексика английского языка имеет более абстрактный характер. Конкретизация (11\%) тем не менее, встречается в отдельных случаях.

Транскрипция (8\%) в основном применена при переводе названий городов.

При анализе приемов модуляции и калькирования не наблюдается.

Проведенный анализ позволил выделить основные переводческие трансформации, помогающие переводчику осуществить адекватный перевод официальной информации.

\section{ЛИТЕРАТУРА}

1. Комиссаров В.Н. Теория перевода (лингвистические аспекты). - М.: Высш. шк., 1990. - 253 с.

2. Бархударов Л.С. Язык и перевод: Вопросы общей и частной теории перевода. - М.: 1975. - 240 с.

3. Швейцер А.М. Теория перевода: Статус, проблемы, аспекты. М.: Наука, 1988. - 215 с

4. Швейцер А.М. Перевод и лингвистика. - М.: Воениздат, 1973. - 280 с.

5. Гарбовский Н.К. Теория перевода: Учебник. - М.: Изд-во Моск. Унта, 2004. - 544 с.

6. АЛРОСА| Корпоративный сайт: сайт. - URL: http://www.alrosa.ru/ (дата обращения: 17.01.2020).

( ) Иванова Раиса Петровна (aissa1@yandex.ru), Салгынова Александра Александровна (salgynova18@gmail.com).

Журнал «Современная наука: актуальные проблемы теории и практики» 